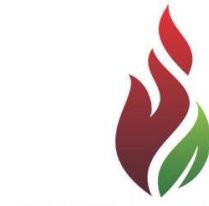

SUSTENERE

Publishing Corporation

\section{CERRADO E PRODUÇÃO ARTESANAL: POSSIBILIDADES DE USO SUSTENTÁVEL DE ESPÉCIES VEGETAIS EM CHAPADA GAÚCHA}

\section{RESUMO}

O uso das partes de espécies vegetais, como base para prática artesanal sustentável, foi a base para este trabalho. O objeto desse estudo é o Cerrado de Minas Gerais, especificamente nas comunidades do Município de Chapada Gaúcha. Buscou-se investigar quais espécies vegetais da região, são compatíveis à produção artesanal. Foi analisado o uso e extrativismo dos frutos, sementes, folhas e demais insumos e resíduos, como possíveis matérias primas para produção artesanal. Para mapeamento de dados técnicos, foram analisadas matérias-primas provenientes de espécies vegetais do Cerrado, comercializadas no Mercado Central de Belo Horizonte. Somado à pesquisa bibliográfica, constatou-se uso de matérias primas, principalmente sementes e folhas. A metodologia estabelecida em campo foi o estudo de caso nas comunidades de Buraquinhos, Ribeirão do Areia e Serra das Araras. Foram cadastradas espécies vegetais utilizadas para produção artesanal nas comunidades e no entorno. A produção artesanal na região é ainda incipiente. A região possui potencial para o desenvolvimento do turismo. Foi realizado um catálogo das espécies vegetais compatíveis à produção artesanal. O resultado apresenta possibilidades o uso de insumos e resíduos para a produção artesanal.

PALAVRAS-CHAVE: Cerrado; Produção Artesanal; Sustentabilidade; Espécies Vegetais; Chapada Gaúcha.

\section{CERRADO AND ARTISAN PRODUCTION: POSSIBILITIES FOR SUSTAINABLE USE OF PLANT SPECIES IN CHAPADA GAUCHA}

\section{ABSTRACT}

The use of parts of plant species as a basis for sustainable artisanal practice, was the basis for this work. The object of this study is the Cerrado of Minas Gerais, specifically in the communities of the municipality of Chapada Gaúcha. This study investigated which plant species in the region, are compatible for artisanal production. We analyzed the use and extraction of fruits, seeds, leaves and other inputs and waste, as potential raw materials for craft production. For data mapping technicians, were analyzed raw materials from plant species of the Cerrado, Central Market sold in Belo Horizonte. In addition to the literature search, we found the use of raw materials, especially seeds and leaves. The methodology established in the field was the case study communities of holes, Ribeirao the Sierra Sand and Scarlet Macaws. Were registered plant species used for artisanal communities and the environment. Craft production in the region is still incipient. The region has potential for tourism development. We carried out a catalog of compatible plant species for artisanal production. The result shows the potential use of inputs and waste to artisanal production.

KEYWORDS: Cerrado; Artisan Production; Sustainability; Plant Species; Chapada Gaúcha.
Nature and Conservation, Aquidabã, v.8, n.1, Nov, Dez 2014, Jan, Fev, Mar, Abr, Mai, Jun, Jul, Ago, Set, Out 2015.

ISSN 2318-2881

SECTION: Articles

TOPIC: Ecoturismo

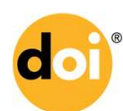

DOI: $10.6008 /$ SPC2318-2881.2015.001.0003

Nadja Maria Mourão

Universidade do Estado de Minas Gerais, Brasil http://lattes.cnpq.br/5407300132397950 nadjamourao@gmail.com

Rita de Castro Engler

Universidade do Estado de Minas Gerais, Brasil http://lattes.cnpq.br/1848076566428564 rcengler@uou.com.br

Received: 30/09/2015

Approved: 30/09/2015

Reviewed anonymously in the process of blind peer.

Referencing this:

MOURÃO, N. M.; ENGLER, R. C. Cerrado e produção artesanal: possibilidades de uso sustentável de espécies vegetais em chapada gaúcha. Nature and Conservation, Aquidabã, v.8, n.1, p.22-32, 2015. DOI: http://dx.doi.org/10.6008/SPC23182881.2015.001.0003 


\section{INTRODUÇÃO}

O Cerrado é o segundo maior bioma brasileiro, superado em extensão pela Floresta Amazônica, abrangendo aproximadamente um quarto do território. Reforçam a importância da natureza no país que possui uma das mais ricas flora do planeta. É incipiente ainda o conhecimento dessa diversidade, no entanto, considera-se que o Brasil abriga $15 \%$ de toda a flora mundial. Dessa porcentagem, em torno de 1,5\% das espécies estão restritas ao Cerrado.

Pela sua relevância ecológica, esse ecossistema é considerado como 'hotspot' para a conservação da biodiversidade mundial, conforme Carvalho (2007), Klink e Machado (2005), Brandon et al. (2005) apud Saraiva e Sawyer (2007). Hotspot é um termo usado para designar toda área prioritária para conservação, ou seja, de alta biodiversidade e ameaçada no mais alto grau de risco.

A heterogeneidade fisionômica e alta biodiversidade são evidenciadas na rica quantidade de uso e manejo do Cerrado pelas populações humanas que o habitaram historicamente. De acordo com Ribeiro (2005), os recursos utilizados incluem caça, pesca, madeira, óleos, fibras, plantas medicinais, frutos nativos, formando um complexo cultural cujas origens remontam há mais de 12 mil anos e chegam até a atualidade.

Em Minas Gerais o cerrado abrange $308.000 \mathrm{Km}^{2}$, ocupando área de $53 \%$ do território do estado e a $17 \%$ do cerrado do brasileiro. Está presente principalmente nas regiões do Alto Jequitinhonha, Norte, Noroeste, Alto Paranaíba, Triângulo e Alto São Francisco (RIBEIRO, 2000).

Conforme Oliveira Filho (2008), a maior parte das espécies raras do país é natural do Cerrado, mais precisamente em Minas Gerais (cerca de 550 espécies), devido a grande quantidade de endemismos pontuais nos campos rupestres da Cadeia do Espinhaço, um dos tipos fitofisionômicos do Cerrado.

O Cerrado apresenta, portanto, uma imensa importância econômica, social e ecológica. Entretanto ele se constituiu, nas últimas décadas, em uma grande fronteira agrícola, que teve como consequência em enorme perda da sua área original, resultado de desmatamentos, queimadas, uso de fertilizantes químicos e agrotóxicos e exploração indiscriminada da flora e fauna, conforme MMA (2005).

Em quaisquer ambientes, serviços e produtos, o design pode e deve contribuir efetivamente para a valorização dos recursos naturais, como aponta Bistagnino (2009). Assim, nesta pesquisa parte do mestrado em Design da Universidade do Estado de Minas Gerais, foram investigadas quais seriam as possíveis contribuições para incentivar a sustentabilidade na produção artesanal a partir de resíduos vegetais do Cerrado Mineiro. Além disso, foram estudadas estratégias para promover materiais, técnicas e processos que valorizem o território e que podem ser aplicadas e aperfeiçoadas, como ferramenta para a produção artesanal, preservando a identidade local. 


\section{Produção Artesanal}

Barroso Neto (2001) define o artesanato, ou produção artesanal, como toda atividade produtiva de objetos e artefatos realizados manualmente, ou com a utilização de meios tradicionais ou rudimentares, com habilidade, destreza, apuro técnico, engenho e arte. A destreza e habilidade a distância de uma simples atividade manual; bem como a criatividade é evidenciada na inventividade nas formas, uso e funções.

Conforme Independente do caráter final do produto artesanal seja como utilitário, conceitual, decorativo, litúrgico ou lúdico, apresenta um alto valor competitivo no mercado. O produto artesanal apresenta traços culturais característicos, conferindo ao mesmo, o poder de rivalizar no mercado frente a produtos manufaturados cada vez mais baratos, conforme Lima (2005).

Cumpre um papel social importantíssimo por absorver uma mão de obra muitas vezes de baixa qualificação e de maior número de indivíduos. Nesta atividade, Barroso Neto (2001) os artesãos refletem na produção artesanal a sua dignidade e autoestima, que o diferenciam no mercado de trabalho. Apresentam valor cultural, podendo expressar a autenticidade do saber e do fazer popular.

Diante da necessidade de mudança nos processos produtivos sustentáveis, surge o reaproveitamento das partes vegetais deixadas naturalmente no meio ambiente, os resíduos vegetais, com a perspectiva de propiciar um novo processo produtivo para o artesanato local. Lima (2005) relata que o aproveitamento de materiais reduz o custo de produção para as comunidades, na busca de seu desenvolvimento em bases justas, viáveis e ecologicamente corretas, que podem contribuir com a educação ambiental.

Partindo das ponderações anteriores, o objetivo geral do trabalho consistiu em investigar as espécies vegetais nas comunidades do Município de Chapada Gaúcha localizado no Cerrado Mineiro. Busca-se analisar os métodos de utilização dos insumos e resíduos vegetais e incentivar um processo produtivo sustentável nas bases para uma prática artesanal sustentável. Ou seja, em um tripé de integração entre as dimensões econômica, humana e ambiental. A hipótese levantada foi que a grande biodiversidade vegetal do bioma Cerrado na região pesquisada possui propriedades que podem fornecer matéria-prima para a produção artesanal, respeitando a integridade desse ecossistema.

\section{METODOLOGIA}

As etapas da pesquisa constituíram o estudo de caso, conforme Vergara (2005), empregando as metodologias qualitativas, observação participante e entrevistas semiestruturada. A primeira etapa foi instituída por levantamento de dados auxiliares e reconhecendo a área a ser pesquisada. A segunda etapa, registro de dados dos indivíduos vegetais e das atividades artesanais executadas nas comunidades objeto da pesquisa. Na terceira etapa, inserção de dados para 
observação registro e análise das atividades artesanais com a inclusão do design e da identidade territorial. Relata-se a importância da equipe de apoio, composta por diversos profissionais, entre biólogos, geólogos, líderes locais, representantes do município e designers.

O desenvolvimento da pesquisa de campo foi realizado com apoio do ISNP - Instituto Sociedade, População e Natureza, através do edital UNICOM. 2010, com recursos da União Europeia. Em relação aos dados técnicos, acesso ao material e análise foram importantes as contribuições do CETEC, IEF, IBAMA/ICMbio, Emater, Prefeitura de Chapada Gaúcha e UEMG.

Entre vários autores que norteiam a pesquisa bibliográfica, destacam-se os trabalhos em plantas: Lorenzi (2002) e Ribeiro (1996); em relação ao design e sustentabilidade: Bistagnino (2009), Bonfim (1998), Manzini e Vezzoli (2005); em produção artesanal: Lima (2005) e Barroso Neto (2001); e nas metodologias: Vergara (2005), Ludcke e André (1986).

\section{Resíduos vegetais comercializados no Mercado Central de Belo Horizonte}

Para mapeamento de dados técnicos, foram analisadas matérias primas provenientes de espécies do Bioma Cerrado, comercializadas no Mercado Central de Belo Horizonte. Os comerciantes de insumos e resíduos vegetais para produção artesanal e alguns artesãos que utilizam destes materiais para produção foram entrevistados. Somado à pesquisa bibliográfica, realizou-se a identificação de algumas espécies, pelas folhas e sementes comercializadas, conforme Tabela 1.

Dos resíduos vegetais cadastrados alguns podem estar presentes no Cerrado: Jacarandá, Bate Caixa, Guatambu, Chicha; Buriti; Mutambo; Bolsa de Pastor e Olho de Boi. Porém, não se pode afirmar se os nomes correspondem às espécies. Muitas vezes, o nome da semente no comércio de insumos para artesanato, não corresponde ao nome popular da planta. Outras vezes, não é encontrado registros na literatura que se assemelhe à denominação.

Outro fato registrado é o mesmo nome popular para várias espécies, como o Jacarandá. Jacarandá é um nome vulgar designado a diversas espécies, tanto com gênero Jacaranda quanto outros, como Dalbergia miscolobium, chamada popularmente de Jacarandá do cerrado. São nomes comuns a espécies diversas de duas famílias, Bignoniaceae e Fabaceae.

O Bate Caixa e o Guatambu são comprovadamente espécies do Cerrado. Guatambu ou Peroba, Aspidosperma spp, está presente na mata de galeria e mata ciliar de acordo com Ribeiro e Walter (1998) apud Ribeiro (2005); alguns autores ainda citam Cerradão e Cerrado Sentido Restrito.

Duas plantas apresentam o nome popular de Bate Caixa; Salvertia convallariaeodora e Palicourea rígida. Porém, ambas estão presentes no Cerrado; a primeira aparece na literatura como presente em Cerradão e Cerrado Sentido Restrito e a segunda presente em Cerrado Sentido Restrito e Campo Sujo. Pela carência de registros, estes materiais comercializados são de difícil identificação. 
Tabela 1: Recorde da Tabela de Preços dos insumos e resíduos vegetais beneficiados e comercializados no Mercado Central de Belo Horizonte, em 09/09/2011.

\begin{tabular}{|c|c|c|c|c|}
\hline 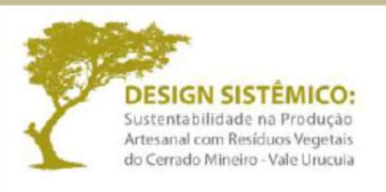 & \multicolumn{4}{|c|}{$\begin{array}{c}\text { RECORTE DA TABELA DE PREÇOS DOS } \\
\text { INSUMOS E RESÍDUOS VEGETAIS BENEFICIADOS } \\
\text { LOJAS DO MERCADO CENTRAL DE BELO HORIZONTE/MG. } \\
\text { DATA: 09/09/2011 }\end{array}$} \\
\hline $\begin{array}{c}\text { Identificação } \\
\text { Visual }\end{array}$ & Especificação popular & LOJA A & LOJA B & LOJA C \\
\hline & $\begin{array}{l}\text { Sementes Chapéu de } \\
\text { Napoleão.Cores diversas }\end{array}$ & $\begin{array}{l}R \$ 15,00 k \\
* R \$ 0,50\end{array}$ & $\begin{array}{l}R \$ 13,00 \mathrm{k} \\
* \mathrm{R} \$ 0,30\end{array}$ & $\begin{array}{l}R \$ 15,00 k \\
* R \$ 0,50\end{array}$ \\
\hline & Sementes de Anajá & $\begin{array}{l}R \$ 12,00 \mathrm{k} \\
* \mathrm{R} \$ 0,10\end{array}$ & $\begin{array}{l}R \$ 12,00 \mathrm{k} \\
* \mathrm{R} \$ 0,10\end{array}$ & $\begin{array}{l}R \$ 12,00 \mathrm{k} \\
* \mathrm{R} \$ 0,10\end{array}$ \\
\hline & Sementes Cinzeiro & $\begin{array}{c}R \$ 13,00 \mathrm{k} \\
* \mathrm{R} \$ 0,20\end{array}$ & $\begin{array}{c}R \$ 13,00 \mathrm{k} \\
* \mathrm{R} \$ 0,20\end{array}$ & $\begin{array}{l}R \$ 13,00 k \\
* R \$ 0,20\end{array}$ \\
\hline & Semente Guatambu & $\begin{array}{l}\mathrm{R} \$ 12,00 \mathrm{k} \\
* \mathrm{R} \$ 0,20\end{array}$ & $\begin{array}{l}R \$ 12,00 k \\
* R \$ 0,20\end{array}$ & $\begin{array}{l}\mathrm{R} \$ 12,00 \mathrm{k} \\
* \mathrm{R} \$ 0,20\end{array}$ \\
\hline & $\begin{array}{l}\text { Sementes Pêssegos do } \\
\text { Cerrado - rolados e } \\
\text { pigmentados }\end{array}$ & $\begin{array}{l}R \$ 15,00 k \\
* R \$ 0,40\end{array}$ & $\begin{array}{c}R \$ 13,00 k \\
{ }^{*} R \$ 0,30\end{array}$ & $\begin{array}{c}R \$ 15,00 k \\
* R \$ 0,40\end{array}$ \\
\hline & Casca do Chichá & $\begin{array}{l}\mathrm{R} \$ 12,00 \mathrm{k} \\
* \mathrm{R} \$ 0,50\end{array}$ & $\begin{array}{l}R \$ 12,00 k \\
* R \$ 0,50\end{array}$ & $\begin{array}{l}\mathrm{R} \$ 12,00 \mathrm{k} \\
* \mathrm{R} \$ 0,50\end{array}$ \\
\hline
\end{tabular}

\section{Cerrado do Vale do Urucuia: Município de Chapada Gaucha}

Em Minas Gerais o cerrado abrange $308.000 \mathrm{Km}^{2}$, ocupando área de $53 \%$ do território do estado e a $17 \%$ do cerrado do brasileiro. Está presente principalmente nas regiões do Alto Jequitinhonha, Norte, Noroeste, Alto Paranaíba, Triângulo e Alto São Francisco (RIBEIRO, 2000). Neste território, encontra-se a Bacia hidrográfica do Rio Urucuia, que nasce na Serra Geral de Goiás e as águas percorrem o vale mineiro até o Rio São Francisco. Especialmente no Vale do Urucuia é preocupante os resultados da perda dos cerrados. Conforme IEF existe distanciamento entre os aspectos socioculturais, econômicos e ambientais desta região com outras regiões.

A cidade de Chapada Gaúcha está distante de Belo Horizonte por 730 km, encontra-se no semiárido do Norte de Minas Gerais, em uma região carente de projetos socioambientais. Possui uma população de 10.792 habitantes, em uma área territorial de $3.215 \mathrm{Km}^{2}$. As atividades econômicas desenvolvidas na região, de acordo com levantamento do IBGE, estão concentradas em três áreas: serviços, agropecuária e indústria.

A antiga Vila dos Gaúchos, hoje município de Chapada Gaúcha, teve seu início de povoamento no ano de 1976. Os gaúchos vieram pelo PADSA - Projeto de Assentamento Dirigido 
a Serra das Araras, que agregou os municípios de Formoso, Arinos, Januária, São Francisco ao povoado da Vila dos Gaúchos, conforme IBGE (2010). No entorno do município estão localizadas duas Unidades de Conservação Estaduais - Parque Estadual Serra das Araras e Reserva Estadual de Desenvolvimento Sustentável Veredas do Acari. Situado na divisa dos estados de Minas Gerais e Bahia, o Parque Grande Sertão Veredas - Unidade de Conservação Nacional é uma das atrações turísticas na região.

\section{RESULTADOS}

Os insumos e resíduos vegetais gerados em Chapada Gaúcha não atendem e provavelmente não atenderão ao comércio do Mercado Central de Belo Horizonte. Primeiramente, pela acentuada distância da capital e porque o mercado de artesanato do Distrito Federal, mais próximo, se identifica melhor com o produto.

Mas, os municípios do Vale do Urucuia podem desenvolver o extrativismo de resíduos vegetais através do manejo sustentável. A riqueza de variedades e a qualidade nos materiais podem acelerar o desenvolvimento sustentável das comunidades. Assim, são relevantes os registros da pesquisa.

\section{Espécies Vegetais em Chapada Gaúcha}

Foi realizada uma demonstração de levantamento florístico ${ }^{1}$, para exemplificar os procedimentos de levantamento de espécies vegetais em uma determinada área. Foram coletados dados das espécies ao entorno das comunidades selecionadas para a pesquisa, pela equipe de biólogos e geólogos. Algumas espécies foram identificadas em diversas áreas do vale do Urucuia, conforme figura 1 e 2. Todas as imagens são registros da pesquisa, em 2011.

Foram cadastradas vinte e uma espécies vegetais utilizadas na produção artesanal, em Chapada Gaúcha. As espécies vegetais coletadas no município foram registradas geograficamente - GPS, pela equipe do projeto e identificada com a colaboração dos agricultores locais e instituições parceiras. São elas: Buriti (Mauritia flexuosa, Arecaceae); Bate Caixa (Salvertia convallariaeodora); Bolsa de Pastor (Zeyheria digitalis (Vell.) Hoehne); Caroba (Jacaranda pteroides); Cinzeiro (Vochysia tucanorum Mart); Chapéu de Napoleão (Thevetia peruviana); Douradinha (Palicourea rígida); Falso Pau brasil (Caesalpinia peltophoroides); Fava d'anta (Dimorphandra mollis Benth); Guatambu (Aspidosperma spp); Jacarandá (Dalbergia nigra); Jacarandá do Cerrado (Dalbergia

\footnotetext{
${ }^{1}$ A demonstração de um levantamento florístico foi realizada através do Método de Ponto Quadrante ("Point Centered Quarter" - Cottam e Curtis 1956, Müller-Dombois e Elemberg 1974 apud Silva, 2008). Esta pesquisa não realizou efetivamente um levantamento florístico, pois todos os dados da região, foram fornecidos pelo IEF/MG - Parque Serra das Araras e pelo ICMbio/IBAMA - Parque Grande Sertão Veredas.
} 
miscolobium); Jatobá (Hymenaea courbaril); Mutambo (Guazuma ulmidifolia); Pau doce (Vochysia cf. Ferruginea); Pau santo (Vismia spp.); Pau terra do Campo (Qualea Grandiflora, Mart.); Pente de macaco (Pithecoctenium crucigerum); Saboneteira (Sapindus saponaria); Tingui (Magonia pubescens); Urucum (Bixa orellana).
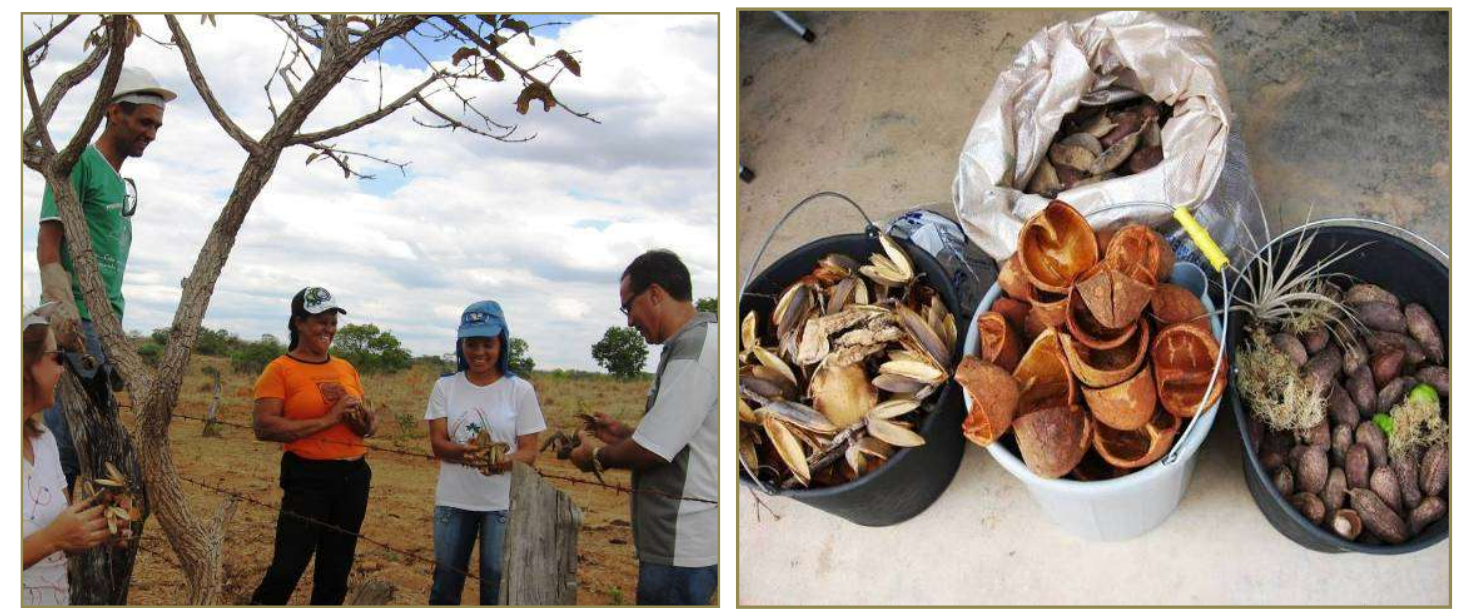

FIGURA 1 e 2: Insumos e resíduos vegetais coletados no Vale do Urucuia.

\section{Produção Artesanal com resíduos vegetais nas comunidades}

Em visita às comunidades, foram registradas as atividades artesanais realizadas pelos artesãos, somente com utilização de resíduos e insumos vegetais, como biojoias, adornos, objetos utilitários e mobiliários. Além da realização do levantamento demonstrativo de espécies vegetais, foi realizado levantamento das comunidades que realizam atividades artesanais materiais de origem vegetal. Verificou-se que os artesãos, na maioria, são produtores rurais agroextrativistas. Executam as atividades de extração e beneficiamento com conhecimento da preservação ambiental. Outros utilizam matéria-prima da Reserva Sustentável do Acari, sob a supervisão do IEF - Instituto Mineiro de Florestas.

As comunidades pesquisadas foram: Buraquinhos, Ribeirão do Areia e Serra das Araras. Foi observada em cada uma, as práticas de produção artesanal, através das oficinas de Design, Identidade e Cultura. O termo oficinas refere-se à aplicação de atividades que promovam o conhecimento, em curto tempo2; aprendizado e prática são executados no ambiente sugerido. Neste caso, desenvolveu-se uma proposta sintética com conteúdos básicos de design, cultura e identidade, especificamente para o público das comunidades da pesquisa. Na sequencia das figuras $3,4,5,6,7$ e 8 , são apresentadas as comunidades e alguns produtos artesanais das mesmas, utilizando insumos e resíduos vegetais.

\footnotetext{
${ }^{2} \mathrm{O}$ tempo de uma oficina depende da relação entre o conteúdo e público alvo. Fatores como número de participantes, material e recursos também alteram o tempo de duração.
} 

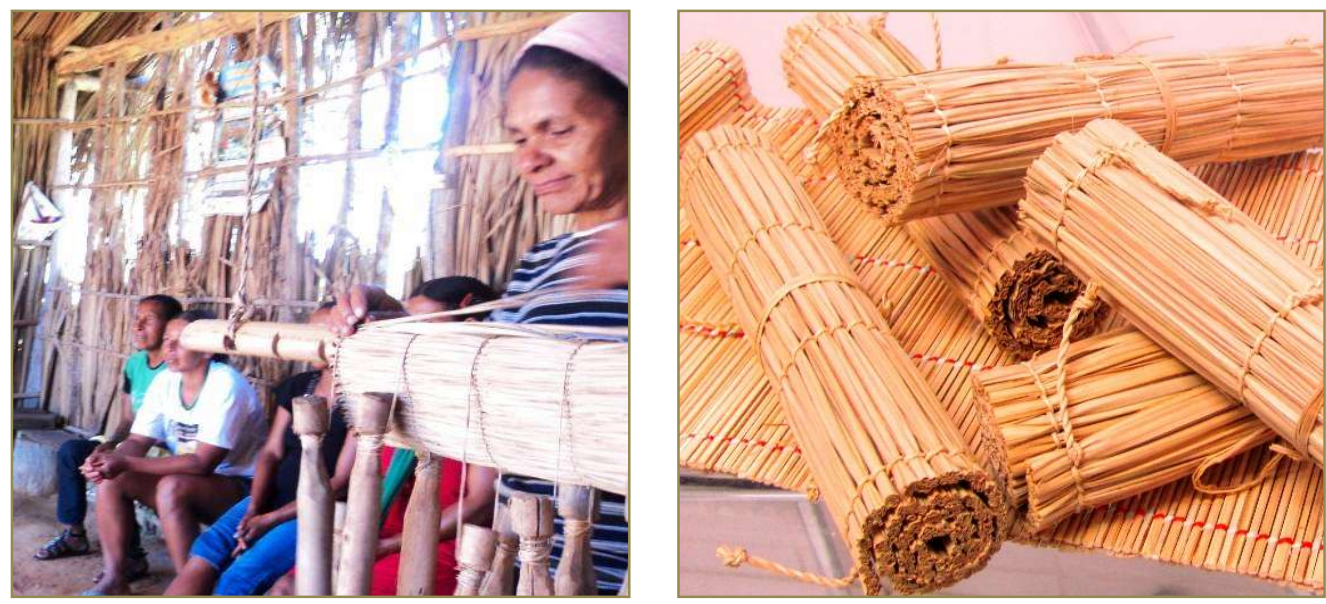

Figura 3 e 4: Comunidade de Buraquinhos e a produção de esteiras com a palha do buriti. São produzidos vários modelos e tamanhos.
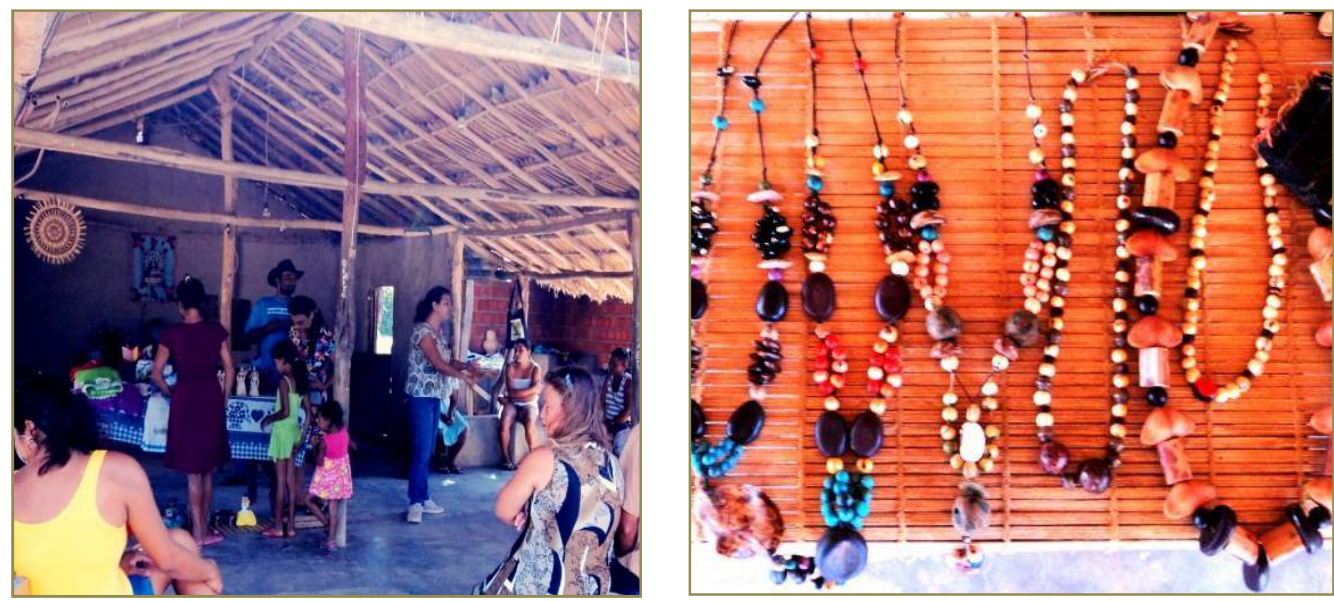

Figura 5 e 6: Comunidade de Ribeirão do Areia e a produção de biojoias, com diversas sementes (Mutambo, Falso Pau Brasil, Chapéu de Napoleão)
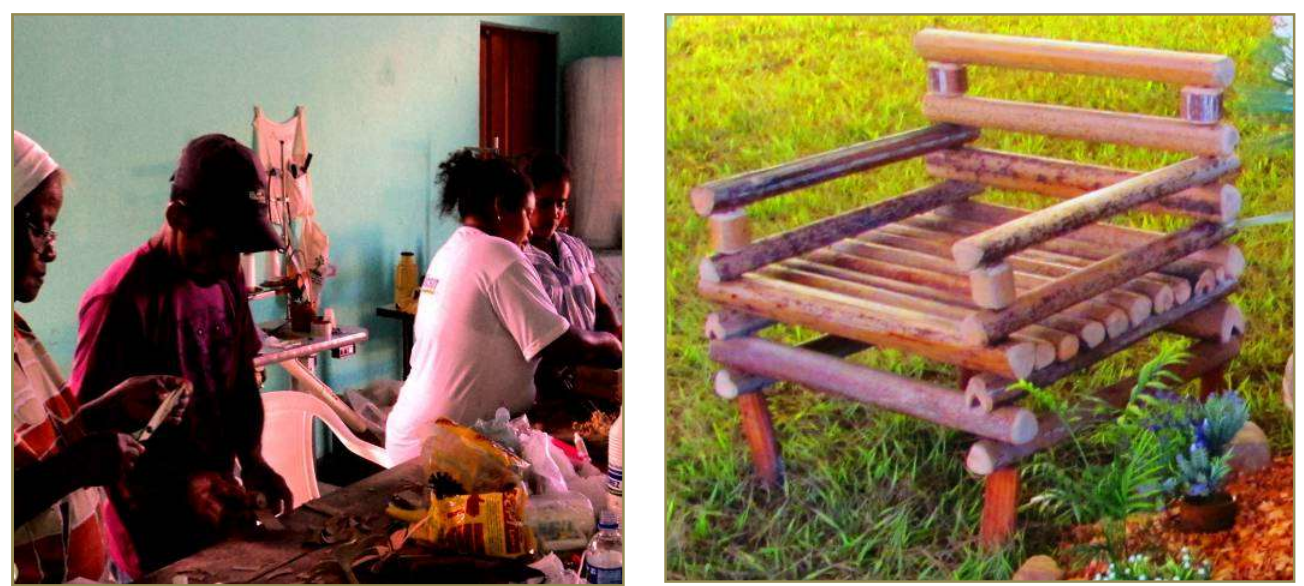

Figura 7 e 8: Comunidade de Serra das Araras e a produção de bancos, utensílios e peças de decoração partes do buriti.

Foram verificados quais materiais de origem vegetal são utilizados na produção artesanal. Entre muitos, destacam-se os produtos dos buritis (bancos, mesas, esteiras, cestos, etc.), das sementes de Mutambo, Falso Pau Brasil, Chapéu de Napoleão (bijoias e quadros). 


\section{ANÁLISE DOS RESULTADOS}

A produção artesanal na região é ainda insipiente. Porém, a região possui potencial para o desenvolvimento do turismo e em economia criativa. O resultado comprova a importância da manutenção no bioma pelas comunidades, possibilitando o uso de insumos e resíduos para a produção artesanal. Foi realizado um catálogo das espécies vegetais para conhecimento das mesmas no processo de utilização compatível à sustentabilidade. È uma boa área para atuação do design sistêmico.

A pesquisa bibliográfica sobre o artesanato forneceu relevantes informações não só sobre a sua importância econômica e cultural, como também sobre os processos artesanais, em especial os provenientes de materiais vegetais. Foi observada a variedade de matérias e as diversas utilizações, além de algumas ferramentas e técnicas empregadas na produção artesanal com materiais vegetais.

Houve uma grande dificuldade na identificação de que espécie advém o resíduo vegetal, pois muitas vezes o nome popular faz referência a amplas espécies, e nesse caso há um fator importante. O não conhecimento da espécie pode implicar excessiva exploração de matéria-prima, causando um prejuízo ecológico mais sério. O resíduo vegetal é de fundamental importância no processo de ciclagem de nutrientes para o solo, enriquecendo - o dos minerais que mais tarde entrarão novamente no ciclo biológico. Especial importância deve ser conferida a extração de frutos e sementes. Cada espécie tem na natureza um número mínimo de sementes necessárias à manutenção da sua espécie. É o que chamamos de banco de sementes. A extração incorreta desse recurso pode levar a extinção local da espécie.

As oficinas possibilitaram ao pesquisador observar o grupo no desenvolvimento das atividades artesanais (materiais e técnicas), dos conteúdos e da identidade. Esta atividade atendeu ao objetivo de integração dos participantes, incentivando-os para troca de informações com a equipe do projeto. Foram registrados nos produtos os resultados da percepção ambiental, que contribuem aos artesãos, a conhecerem melhor o meio ambiente no qual estão inseridos.

\section{CONCLUSÕES}

Registra-se a necessidade de outros estudos e entendimentos da estrutura e funcionamento do ecossistema a ser explorado, enfatizando o ciclo biológico de cada espécie, a fim de promover um manejo adequado e manter a taxa de produtividade necessária à manutenção desse sistema. Considera-se neste caso, a importância do conhecimento das espécies vegetais na região e o uso de seus recursos (alimentação, medicamentos e no artesanato) no desenvolvimento de estratégias para promover a economia local.

As sementes e frutos das espécies do Cerrado: Bate Caixa, Caroba, Chapéu de Napoleão, Guatambu, Jacarandá do Cerrado, Mutambo, Pau Doce, Pau Terra do Campo, Pente de Macaco e 
Saboneteira, são usadas pelos artesãos do centro-oeste e do sudeste. Portanto, estas espécies possuem mercado garantido para comercialização e não servem como alimento. No entanto, se houver investimentos em capacitações para extrativismo sustentável destes materiais, poderão geram novas possibilidades para a economia local.

Evidenciam-se alguns pontos relacionados a uma possível continuidade da pesquisa. Existe um extenso número de materiais utilizados e não catalogados; por se restringir a uma pequena parcela de produção artesanal, como verificado em Chapada Gaúcha. Além disso, o tema é de importância para todos os demais biomas que sofrem de esgotamento de materiais vegetais, com carência de conhecimento e desenvolvimento do extrativismo sustentável.

\section{REFERÊNCIAS}

BARROSO NETO, E.. O que é o Artesanato. Módulo 1. Eduardo Barroso, 2009.

BISTAGNINO, L.. Design Sistêmico. Pregetalle là sostentabilità produttiva e ambientalle. Torino: Slow Food Editore, 2008.

BONFIM, G. A.. Design e Informação. São Paulo: Design \& interiores, v.9, n.49, 1995.

BRASIL. Constituição Federal de 1988. Art. 24, Título VIII, Capítulo VI, $\S 4^{\circ}$, capítulo sobre o meio ambiente. Brasília, 1988.

CARVALHO, I. S. H.. Potências e limitações do uso sustentável da Biodiversidade do Cerrado: um estudo de caso da Cooperativa Grande Sertão Veredas do Norte de Minas Gerais. Resumos do V CBA Uso e Conservação de Recursos Naturais, 2007.

IBGE. Instituto Brasileiro de Geografia e Estatística. Produção da extração vegetal e da Silvicultura. Diretoria de Pesquisas. Coordenação de Agropecuária, 2010.

LIMA, R.. Artesanato de tradição: cinco pontos em discussão. São Paulo, 2005.

LORENZI, H.. Árvores brasileiras: manual de identificação e cultivo de plantas arbóreas nativas do Brasil. 4. ed. Nova Odessa: Instituto Plantarum, 2002.

LÜDKE, M.; ANDRÉ, M.. Pesquisa em educação: abordagens qualitativas. São Paulo: EPU, 1986.

MANZINI, E.; VEZZOLI, C.. O desenvolvimento de produtos sustentáveis: os requisitos ambientais dos produtos industriais. São Paulo: Edusp, 2002.

MENDES, X.. História do vale do Rio Urucuia em Minas Gerais. Academia Planaltinense de Letras, 2011.

MINISTERIO DO MEIO AMBIENTE. Consumo Sustentável: Manual de Educação. Brasília: Consumers International/ MMA/ MEC/IDEC, 2005.

MOURÃO, N. M.. Sustentabilidade na produção artesanal com resíduos vegetais: uma aplicação prática de design sistêmico no Cerrado Mineiro. Dissertação (Mestrado em Design, Inovação e Sustentabilidade) - PPGD/Universidade do Estado de Minas Gerais, Belo Horizonte. 2011.

OLIVEIRA FILHO, A. T.; SCOLFORO, J. R.; SILVA, C. P. C.. Compilação e caracterização das espécies arbóreas da flora nativa de Minas Gerais. In: OLIVEIRA FILHO, A. T.; SCOLFORO, J. R.. Inventário florestal de Minas Gerais: Espécies Arbóreas da Flora Nativa. Lavras: UFLA, 2008.

RIBEIRO, J. F.. Cerrado: matas de galeria. Planaltina: Embrapa-CPAC. 1998. 
RIBEIRO, J. F.. História ecológica do sertão mineiro e a formação do patrimônio cultural sertanejo. In: DAYRELL, C. LUZ, C.. Cerrado e desenvolvimento: tradição e atualidade. Montes Claros, 2000.

RIBEIRO, J. F.. Florestas anãs do Sertão: O Cerrado na História de Minas Gerais. Belo Horizonte: Autêntica, 2005.

SARAIVA, N.; SAWYER, D.. Análise do potencial econômico e socioambiental do artesanato do Buriti em comunidades tradicionais nos Lençóis Maranhenses. In: Encontro da Sociedade Brasileira de Economia Ecológica, 7. Anais. Fortaleza, 2007.

SILVA, C. E. M.. O Cerrado em disputa: Apropriação global e resistências locais. Brasília: Confea, 2008.

VERGARA, S. C.. Métodos de pesquisa em administração. São Paulo: Atlas 2005. 